\section{A) Check for updates}

Cite this: Analyst, 2020, 145, 1310

\title{
Dual isotope system analysis of lead white in artworks $\dagger$
}

\author{
Laura Hendriks, (D) * $\star^{\mathrm{a}, \mathrm{b}}$ Stefan Kradolfer, (D) * $\star^{\mathrm{b}}$ Tiziana Lombardo, (D) ${ }^{c}$ Vera Hubert, ${ }^{c}$ \\ Markus Küffner, ${ }^{d}$ Narayan Khandekar, ${ }^{e}$ Irka Hajdas, (D) ${ }^{a}$ Hans-Arno Synal, (D) ${ }^{a}$ \\ Bodo Hattendorf (ID ${ }^{b}$ and Detlef Günther ${ }^{b}$
}

\begin{abstract}
Isotopic studies are gaining much interest in heritage science, as they can provide insight into a material's age and provenance. Radiocarbon $\left({ }^{14} \mathrm{C}\right)$ dating affords a time frame for the materials being studied, thus providing a historical context, whereas the specific pattern of lead isotope ratios may be used to set geographical constraints on the source of the original materials. Both methods require invasive sampling from the object, and henceforth limits their respective application. With the focus on lead white paint $\left(2 \mathrm{PbCO}_{3} \cdot \mathrm{Pb}(\mathrm{OH})_{2}\right)$, in this study we extract the time of production of the pigment from the carbonate anion by radiocarbon dating while its origin is traced by lead isotope analysis on the cation. The methodology was applied to 12 British and 8 Swiss paintings from the $18^{\text {th }}$ to $20^{\text {th }}$ century, with known dates and provenance. The ${ }^{14} \mathrm{C}$ analysis of the lead white in combination with the organic binder and canvas alone places all objects between the $17^{\text {th }}$ and $20^{\text {th }}$ centuries, which is in agreement with their signed date, wheras the lead isotope analysis of all samples are consistent with lead ores from European deposits. In most of the cases the combined results are consistent with the art historical data and prove that isotope analysis is intrinsic to the object. This feasibility study conducted on paintings of known age demonstrates the possibility to maximize the information output from lead white paint, thus increasing the benefits of a single sampling.
\end{abstract}

Received 21st November 2019 Accepted 30th December 2019 DOI: 10.1039/c9an02346a rsc.li/analyst such as titanium white or zinc white were introduced. ${ }^{2}$ Lead white is one of the oldest man-made pigments and many recipes describe its manufacturing process. The general outline involves the corrosion/oxidation of metallic lead under the combined action of oxygen, carbon dioxide and acetic acid, which delivers a bench stable, white compound ${ }^{3,4}$ which is usually referred to as basic lead carbonate or the pigment lead white. However it is worth noting that it is a very often a mixture of hydrocerussite, a lead carbonate hydroxide, and cerussite, a lead carbonate, in different proportions. Owing to its wide use over millennia, the detection of lead white in a work of art alone does not constitute a marker for dating. Nonetheless, owing to the increased interest for isotopic studies in heritage science, lead white has a large potential as isotopic tracer. ${ }^{5}$

The source of the lead ores used in the production of the lead white pigment can be traced and narrowed to locations by lead isotope analysis, which can then serve as proxy for the provenance of the object. $^{6-9}$ The variability between the different lead isotopes and different ores is a result of them being at the end of the decay chain of uranium and thorium. The primary ratios change by an increase in the amount of the radiogenic ${ }^{208 / 207 / 206} \mathrm{~Pb}$, whereas the ${ }^{204} \mathrm{~Pb}$ is not a decay product. A particular example which benefitted from this analysis was the authentication of Vermeer's Saint Praxedis, ${ }^{10}$ 
where the lead isotope analysis provided indisputable evidence that the painting was made in Holland and upon comparison with lead white from another Vermeer's picture suggest that both paintings were rendered from the same batch of pigment. During the Middle-Ages, Venice was the major production location for lead white, producing a high quality pigment, "Venetian white". By the $17^{\text {th }}$ century, it was delocalized to Holland which became the leader in lead white production in the $18^{\text {th }}$ century, where the traditional Stack process was implemented into large scale production and become known as the Dutch process. ${ }^{11}$ By the end of the $18^{\text {th }}$ century, the Netherlands was home to over 35 lead white factories, from which large exports to other European countries took place. ${ }^{12}$ In England, following the embargo policies of Elizabeth I, the British lead white industry took off some years after that in Holland, which is extensively reviewed in the work of Rowe (2017). ${ }^{13}$

The radiocarbon age gained from the carbonate delivers insight regarding the time or method of production of the white pigment. Indeed, depending on the manufacturing process, the carbonate anion will carry a defined ${ }^{14} \mathrm{C}$ signature. In the case of the traditional Stack process, which involves the oxidation of metallic lead over fermenting organic material, the atmospheric ${ }^{14} \mathrm{C}$ signature is trapped in the carbonate and thus can readily be dated. Prior work made use of this property to date ancient cosmetics from the Greeks and Egyptians, ${ }^{14}$ whereas $21^{\text {th }}$ century Stack produced lead white was dated to the year of production with the help of the "bomb peak" calibration curve. ${ }^{15}$ By the beginning of the $19^{\text {th }}$ century, new patents replaced the atmospheric source of carbon dioxide with burned coal or other petrochemical feedstock and salt dissolution, which causes a drastic impact on the ${ }^{14} \mathrm{C}$ signature. These geological sources are devoid of ${ }^{14} \mathrm{C}$, and upon ${ }^{14} \mathrm{C}$ dating translate to ages which are several thousand years. Therefore, the abundance of ${ }^{14} \mathrm{C}$ in lead carbonate can provide information regarding its manufacturing process, as well as the time of production.

The data from such an isotopic analyses can place an object into its historical context. Thus, when focusing on the lead white pigment specifically, analysis provides insights into its production over time emphasizing when the global lead market extended beyond local ores and became a Europeanwide market. However, to access this information invasive sampling of a work of art is necessary. $\mathrm{Pb}$ isotope ratios can be measured from as little as $50-200 \mu \mathrm{g}$ paint, ${ }^{7}$ whereas ${ }^{14} \mathrm{C}$ analysis of the lead white carbonate requires more material, between $1 \mathrm{mg}^{15}$ to $20-25 \mathrm{mg}$. ${ }^{16}$

Each technique focusses on a specific ion only, either the carbonate anion for ${ }^{14} \mathrm{C}$ or the $\mathrm{Pb}$-cation, meaning that in both cases the information potential of the sample is not fully accessed. Consequently, there is a need to improve micro-analysis in order to maximise the research output by combining both techniques. The goal of this work is to combine the two isotope systems to gain more insights from a single painting sample that requires minimal sampling.

\section{Experimental section}

\section{Samples}

Two sets of paintings, British and Swiss, with documented age and provenance were analysed. The Harvard Art Museums provided 12 canvas tacking margins cut from British paintings that had been lined in their studio. The selection of clippings contained both the ground and the canvas. The Swiss National Museum collection allowed sampling on 7 objects, where minute amounts of material were sampled from the side of the canvas, in several cases hidden by the frame rebate. An additional object belonging to the SIK-ISEA, painted by Franz Rederer, a Swiss artist of the $20^{\text {th }}$ century, which had been previously investigated ${ }^{15,17}$ was also included in the study. The paintings date of creation ranged from the $17^{\text {th }}$ to $20^{\text {th }}$ century. To these two sets of samples, a series of lead white oil paint reconstructions were prepared for quality control of the analyses. They consisted of linseed oil (\#73504, Kremer Pigmente $\mathrm{GmbH} \& \mathrm{Co}$, Aichstetten/Allgäu, Germany), lead white produced following the Stack process (HART project $\S^{18}$ ) and industrial produced lead white $\# 46000$, Kremer Pigmente $\mathrm{GmbH} \& \mathrm{Co}$, Aichstetten/Allgäu, Germany) as well as calcium carbonate (Kremer Pigmente GmbH \& Co, Aichstetten/Allgäu, Germany).

\section{Sample characterisation}

Owing to the complexity of works of art, where multiple layers of paint often come into play, a complete characterisation of the paint components was necessary. The workflow leading to sample selection involved a combination of X-ray fluorescence (XRF), Fourier-transformed infrared (FTIR) and Raman spectroscopy of the samples. Preliminary non-contact energy dispersive XRF analyses were performed in situ on the painting, provided an elemental distribution in a first step of selecting possible sampling points. Paint locations bearing lead white as main component were targeted and sampled. Further FTIR and Raman spectroscopy enabled the identification of the binder, dyes, varnishes and fillers. This set of techniques is often used in combination because they are complementary and allow a thorough description of the materials used in the painting. ${ }^{19,20}$ This workflow allowed for the identification of additional interferences when carrying out the ${ }^{14} \mathrm{C}$ and $\mathrm{Pb}$ isotope analysis. The presence of other carbonates, such as chalk, would interfere with the dating of the lead white pigment, and any organic pigment or carbon black interferes in dating the binder. When targeting a specific carbon source, one must be aware of any other external carbon sources which may come into play. A physical separation of all different carbon sources is not a trivial process or even possible, but different strategies allow for the selective removal

$\S$ Historically Accurate Oil Painting Reconstruction Techniques, in short the HART project was part of the De Mayerne Programme led by Professor Dr Jaap Boon and funded by the Netherlands Organisation for Scientific Research (NWO) between 2002 to 2005, where Dr Carlyle was Principle Investigator (Carlyle, HART Project Report, 2005). 
and/or analysis of specific carbon sources (see "14C dating"). Similarly, for lead isotopes, the presence of other lead containing pigments and additives is an issue as their respective isotopic patterns will overlie those from the lead white. Moreover, the presence or absence of mercury containing additives is of particular interest as it has an isobaric interference with one lead isotope. The technical details are given in the ESI (page S4†).

\section{${ }^{14} \mathrm{C}$ dating}

Depending on the targeted material, a specific sample treatment was applied. In the case of the canvas clippings, the paint was mechanically separated from the textile fibres. The canvas material was then cleaned by Soxhlet extraction (chloroform, hexane, acetone, ethanol $)^{21}$ followed by standard acidbase-acid cleaning procedures (0.5 M HCl, 0.1 M NaOH). ${ }^{22}$ The cleaned canvas material was converted to graphite in an automated graphitisation system (AGE). ${ }^{23}$ The paint fragments were all cleaned by acetone as precaution to ensure removal of potential varnish. The lead carbonate $\mathrm{CO}_{2}$ was extracted by sealing the paint material in quartz tubes under vacuum and heating in a muffle furnace for $30^{\prime}$ at $350{ }^{\circ} \mathrm{C}^{24}$ The produced carbon dioxide was transferred via cryotrapping into smaller Pyrex® tubes and sealed. In the case where no other carbon bearing material other than the binder were identified, the additional dating of the organic binder was pursued, i.e. acidic wash to remove carbonates followed by direct combustion. All radiocarbon measurements were conducted on the MICADAS ${ }^{14} \mathrm{C}$ dedicated system in the Laboratory of Ion Beam Physics, ETH Zurich. ${ }^{25,26}$ Canvas material was measured as graphite, the lead white and organic binder via the gas interface, ${ }^{27,28}$ which allows the measurement of $\mathrm{CO}_{2}$ prepared in the Pyrex® tubes $^{29,30}$ or by coupling of an elemental analyser (EA) where the sample is first combusted. ${ }^{31}$ The measured radiocarbon ages were converted to calibrated calendar dates using Oxcal v.4.3 software. $^{32,33}$

\section{Lead isotope ratio determination}

The remaining material after ${ }^{14} \mathrm{C}$-analysis was prepared for the lead isotope determination. The samples were digested (see Table S5 in the ESI $\uparrow$ for detailed procedure) and the lead concentration of the resulting solutions were determined using a quadrupole based inductively coupled plasma mass spectrometer (Q-ICPMS; Agilent 7500cs, Agilent Technologies, Santa Clara, USA). All samples were further diluted to $400 \mu \mathrm{g} \mathrm{kg}{ }^{-1} \mathrm{~Pb}$ and a spike of thallium (200 $\mu \mathrm{g} \mathrm{kg}^{-1}$, NIST SRM997, NIST, USA) was added as an internal standard. ${ }^{34}$ The measurements of the different $\mathrm{Pb}$ isotope ratios were performed on a $\mathrm{Nu}$ plasma HR MC-ICPMS (Nu Instruments Ltd, Wrexham, United Kingdom) in the Laboratory of Inorganic Chemistry, ETH Zurich.

The mass discrimination correction was performed using the empirically determined value for thallium by applying an exponential model. ${ }^{34,35}$ Periodic measurements of a certified $\mathrm{Pb}$ isotope reference material (NIST SRM981, NIST, USA) were made to monitor the stability of the analyses. All ratios can be traced to reference values of SRM981 published values. ${ }^{36,37}$
Correction of mercury overlap to ${ }^{204} \mathrm{~Pb}$ was carried out in a similar fashion by measuring ${ }^{202} \mathrm{Hg}$ and using the mass discrimination value obtained for ${ }^{205,203} \mathrm{Tl}$ to estimate and subtract the ion signal of ${ }^{204} \mathrm{Hg}$. The data were evaluated and plotted by the open software R (version 3.4.3, https:/www.rproject.org). More detailed information concerning the measurements, the data treatment and all the corresponding parameters/data are given in the ESI (pages S14-17†).

\section{Results and discussion}

The following results section is divided into the following subsections; firstly, the ${ }^{14} \mathrm{C}$ ages gained from the lead carbonate are discussed and compared with ages of the canvas or binder. Secondly, the results regarding the $\mathrm{Pb}$ isotopic analysis are presented, which is then followed by a broader discussion regarding the significance of this study.

\section{Radiocarbon results}

The radiocarbon dating results of the paint materials are given in Tables S3 and S4 in the ESI, $\uparrow$ including lead carbonate, the canvas when sampled and the organic binder if deemed suitable.

From the collected data, it is clear that the lead white samples, which range from the $18^{\text {th }}$ to $20^{\text {th }}$ century, were produced following the Stack manufacturing process as the measured ${ }^{14} \mathrm{C}$ is present at atmospheric levels. The calibration of the ${ }^{14} \mathrm{C}$ ages to real calendar ages was conducted with the IntCal13 atmospheric calibration curve ${ }^{38}$ as all objects are pre1950. Some samples show close to modern ${ }^{14} \mathrm{C}$ concentration $\left(\mathrm{F}^{14} \mathrm{C}>1\right)$, thus one may infer the use of the post-atmospheric bomb NH1 calibration, ${ }^{39}$ which results in the same probability distribution as with Intcal13 with the additional extension of the 1950s time window. The resulting broad time intervals are a direct consequence of the numerous wiggles and the plateau shape of the calibration curve between 1700-1950, also known as "Stradivarius gap". ${ }^{40}$ This nickname was given following the unsuccessful attempt in using ${ }^{14} \mathrm{C}$ measurements to date the most famous violins of Antonio Stradivari, which were built in the period from 1700 to $1725 \mathrm{AD}$. This behaviour of the calibration is linked to variations of atmospheric ${ }^{14} \mathrm{C}$ as a consequence of solar activity fluctuations as well as to the increased burning of fossil fuels which dilutes the natural ${ }^{14} \mathrm{C}$ signal, also known as the Suess effect. ${ }^{41-43}$ An example of this unfortunate situation is depicted in Fig. 1, which illustrates the lead carbonate age distribution resulting from the ${ }^{14} \mathrm{C}$ measurement. A precise dating is impossible and multiple time windows are possible, ranging from $16^{\text {th }}$ to mid- $20^{\text {th }}$ century. The same is observed for the dating of the binder and canvas material as displayed in Fig. 2 (sample code LM-161897). Although a more precise dating was not possible, the additional dating of the canvas and the organic binder is of help to constrain the possible time windows, as their respective date ranges agree among each other and the respective calibration is consistent with the signed date of 1813 . 

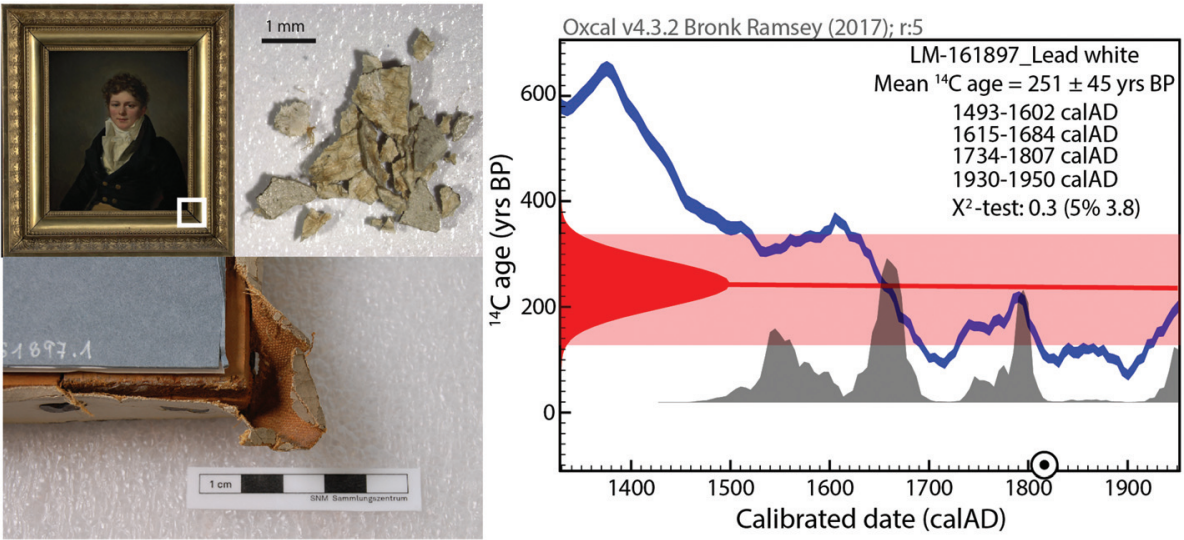

Fig. 1 (Left) Sampling of the portrait of Eric Magnus Louis Grand Hauteville painted in the style of Amélie Munier Romilly (LM-161897). Some sample material was collected below the frame from excess material around the wooden stretcher. (Right) Calibration process of the measured radiocarbon age (red), in this case the mean value of two individual lead white measurements (mean ${ }^{14} \mathrm{C}$ age is $251 \pm 45$ years $\mathrm{BP}$ ). The corresponding calendar age is read out at the intersection with the Intcal13 calibration curve (blue) (Reimer et al., 2013) on the $x$-axis (grey histograms). The circled dot indicates the signed date of the painting, i.e. 1813

From Fig. 2 a similar conclusion can be drawn for half of the investigated paintings, where an overlap of the dating of different materials is observed. Clear examples of such overlaps are Marco Ricci and Sir Arthur Stockdale Cope. Such a statement is however only possible as the attributed dates are known. In the case of unknown aged paintings, a precise dating with micro amounts of lead white is for this period impossible and a larger time window must be considered. A smaller measurement uncertainty would be beneficial, but would require more material and multiple measurements. Therefore, it becomes interesting to date, not only the support material or pictorial layer but all together: the pigment, binder and canvas, and then to observe if their respective ${ }^{14} \mathrm{C}$ ages are consistent with one another.

The ${ }^{14} \mathrm{C}$ signature of the carbonate anion is an archive of the lead white industry, as the varying source of $\mathrm{CO}_{2}$ is recorded in the carbonate. What is interesting in the collected data (see ESI: Tables S3 and S4 $\dagger$ ) is the widespread of ${ }^{14} \mathrm{C}$ age indicating an atmospheric ${ }^{14} \mathrm{C}$ source, i.e. produced following the Stack process. Surprisingly, few samples show a fossil fuel signature (>1000 years), which is an indication of a $19^{\text {th }}$ century alternative to the traditional lead white production process. In particular, two objects from the beginning of the $20^{\text {th }}$ century, namely from a Swiss artist dated 1907 (LM-158151) as well as British artist 1901 (Sir Arthur Stockdale Cope) still show the signal of a Stack processed lead white pigment. This observation can be explained by the fact that although alternative processes were numerous, the well-known Dutch lead white industry remained the most robust means of lead white production. Artists favoured Stack/Dutch processed lead white owing to its superior quality. ${ }^{44}$ Thus, although the $19^{\text {th }}$ century was rich in innovations, industries which implemented modern scientific technologies suffered from the competition with the Dutch industry. Homburg and De Vlieger (1996) describe the dominance of the Dutch manufac- turing process as "a victory of practice over science", which is corroborated by Pulsifer (1888) who states that the major factories in France and England mostly reverted to the Dutch process during the $19^{\text {th }}$ century. ${ }^{12,45}$

Nonetheless, two objects carried a depleted ${ }^{14} \mathrm{C}$ signal, which is characteristic of a fossil source and indicative of alternative production methods to the Stack process. The lead white pigment present in the green paint on the reverse of Margrit's portrait (SIK-98511) was determined to be $>5000$ years old. The second sample from this study showing a depleted ${ }^{14} \mathrm{CO}_{2}$ source, belongs to the painting from the British artist Samuel Alken. The ${ }^{14} \mathrm{C}$ data corresponds to an age of $>4000$ years. Two reasons may be plausible for this result, which could not be verified in the frame of this project. Either the high chalk content present in the sample interacted with the oil matrix and biased the thermal extraction of the lead carbonate, or lead white with a depleted ${ }^{14} \mathrm{C}$ signal maybe produced in the Chamber process following James Creed's patent was available to him while working at the Royal Academy School of London.

With the aim of maximising information output from a unique sample, the possibility of radiocarbon dating the organic binder following the extraction of the carbonate age was also pursued. Unfortunately, Raman analysis very often revealed the presence of carbon black (see Tables S1 and S2 in ESI $\dagger$ regarding material characterisation), which is problematic as it introduces a second source of carbon other than

ๆIn comparison to previously published value of 25000 years, ${ }^{15}$ the proposed sample preparation indicates a small bias as a fraction of the oil also reacted, which is generally not an issue as we assume that the pigment and oil are from the same time. The thermal decomposition of lead carbonate to carbon dioxide was proposed as alternative to the hydrolysis approach, which reaches its limitation in the presence of the chalk interference in ${ }^{14} \mathrm{C}$ analysis. It is known that British and Dutch factories added chalk to their lead white to cut the costs. ${ }^{52,53}$ 
Oxcal v4.3.2 Bronk Ramsey (2017); r:5

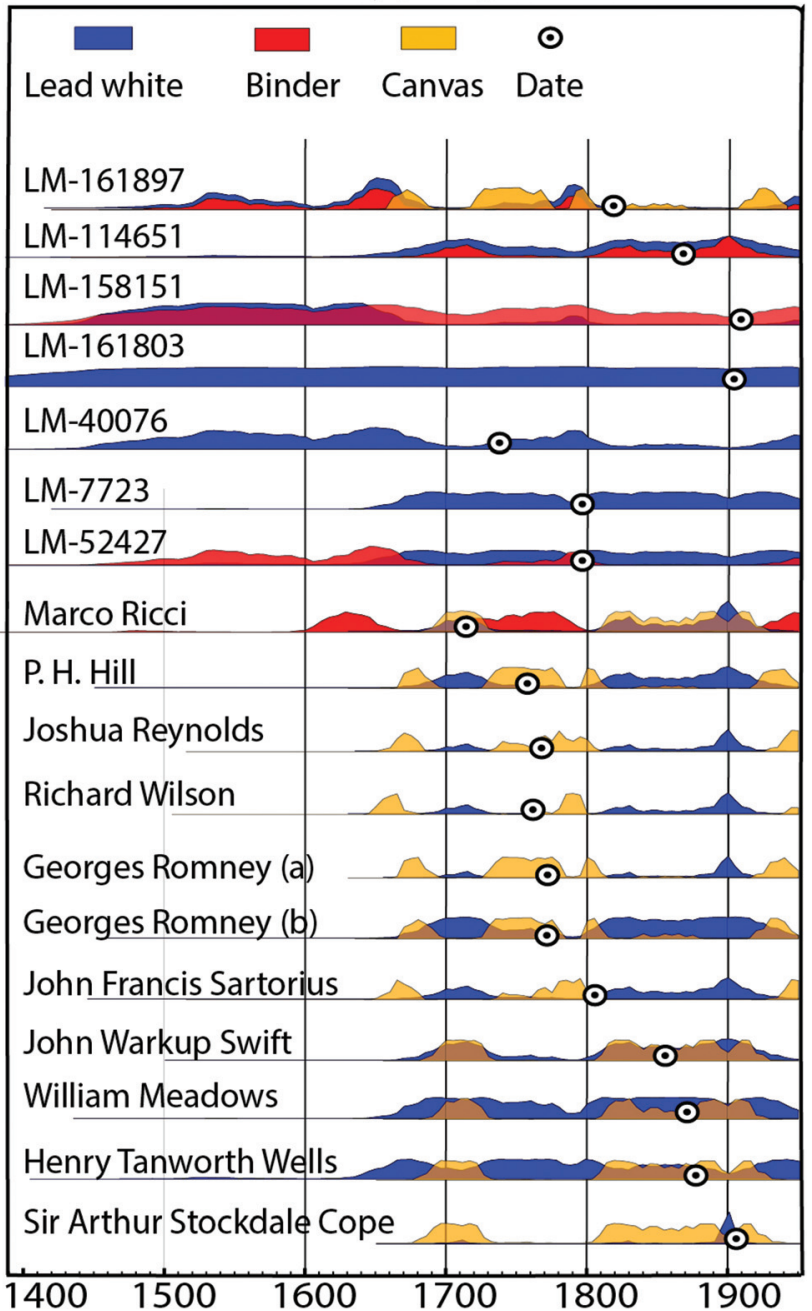

Fig. 2 Overview of the calibrated ${ }^{14} \mathrm{C}$ age gained from the lead carbonate (blue), paint binding media (red) if deemed suitable for radiocarbon analysis and canvas (yellow) when present. The paintings were selected to cover the $17^{\text {th }}$ to $20^{\text {th }}$ century.

the organic binder. When comparing the ${ }^{14} \mathrm{C}$ ages of the canvas, carbonate and organic binder, paint samples where carbon black is identified, are systematically older than the other two components (ESI: Tables S3 and S4†). The age of carbon black can substantially vary as it is produced from burning organic matter, which is not necessarily from the artist's lifetime. With the aim of dating the lead white isotope when carbon black was identified, the binder age is not considered in the further discussion. When samples were collected from tacking margins, the dating of the canvas was also pursued. From Fig. 2, the additional dating of either the canvas or binder reinforces the lead white dating, and supports the idea that artists used material from their time of activity as the ${ }^{14} \mathrm{C}$ ages correlate with the signed date. In some cases, an offset between the lead white's age and the canvas is observed, which can be explained by different usages of the different materials, such as canvas, pigment and organic binder. It is commonly observed that the canvas support predates the signed date by 2-5 years, although some samples show longer "in-built" ages due to recycling. ${ }^{46}$ In contrast, the paint materials, namely the pigment and binding media, may have much longer shelf life's varying from years to decades.

\section{Lead isotope data}

Although pure lead white paint was aimed for during the sampling phase, most samples were not as homogeneous as hoped for and other additives were present. In addition to the oil binder matrix, $\mathrm{CaCO}_{3}$ a commonly used filler ${ }^{47}$ was identified in numerous samples. The influence of these two additives on the isotope ratio was investigated using paint mockups with different $\mathrm{CaCO}_{3}$ to $\mathrm{PbCO}_{3}$ loading similar to prior work. ${ }^{7,8}$ The linseed oil matrix shows no apparent influence on the lead isotope ratios for SRM981-spiked digests (ESI: Figure $55 \dagger$ ) and for lead white oil paint reconstructions (ESI: Figure S6†), while the amount of calcium relative to lead has a significant impact (ESI: Figure $\mathrm{S} 4 \dagger$ ). Our results are comparable to the ones from Fortunato et al. (2005), ${ }^{7}$ i.e. samples containing a Ca-content higher than $700 \mu \mathrm{g} \mathrm{kg}^{-1} \mathrm{CaCO}_{3}$ relative to $400 \mu \mathrm{g} \mathrm{kg}^{-1} \mathrm{PbCO}_{3}$ are strongly biased. Two samples, namely "Alken" and "LM-158151", showed more than $1000 \mu \mathrm{g} \mathrm{kg}{ }^{-1}$ of $\mathrm{CaCO}_{3}$ content and therefore the lead isotope measurements are not accurate and have to be disregarded (see Fig. 3, marked with empty symbols).

Additionally, the influence of mercury was considered. By visually sampling pure white zones, one can theoretically avoid this contamination but vermilion $(\mathrm{HgS})$ can still occur as it was used as additives in the Stack process to counteract the yellowing of the white pigment. $^{44}$ The samples "Joshua Reynolds”, "Ricci”, “LM-40076”, “LM-7723”, “LM-52427”, showed a substantial mercury content and were accordingly corrected, resulting in relative changes of between $0.1 \%$ and $0.4 \%$ to the uncorrected ${ }^{206} \mathrm{~Pb} /{ }^{204} \mathrm{~Pb}$ and ${ }^{207} \mathrm{~Pb} /{ }^{204} \mathrm{~Pb}$ isotope ratios, which were $<0.07 \%$ for all other samples. The presence of vermilion was confirmed by Raman measurements for "Joshua Reynolds" only. Interestingly, Raman analysis for some samples showed specific vermilion bands but no interfering signal was observed in the ICPMS measurements. The reason is that paint samples may be inhomogeneous in particle distribution, thus although vermilion was not identified in some specific samples, it could still be present as seen in the ICPMS data and vice versa.

The interpretation of the lead isotope ratios is in general a non-trivial task and requires some assumptions regarding the lead ore origin and its processing. Indeed, inhomogeneous lead ore bodies from the same site, different ore bodies with the same isotopic signature, (un-)intentionally mixing of two or more ore sources (blending/recycling), fraction effects during metallurgical handling, etc. are all aspects to be considered in the data interpretation as discussed by Baron et al. (2009). ${ }^{48}$

The $\mathrm{Pb}$-isotope ratio results for all samples are shown in Fig. 3, grouped by century and itemized for the different origins (British artists in blue and Swiss ones in red). The individual measurement results are listed in the ESI (Table S10 $\dagger$ ). 


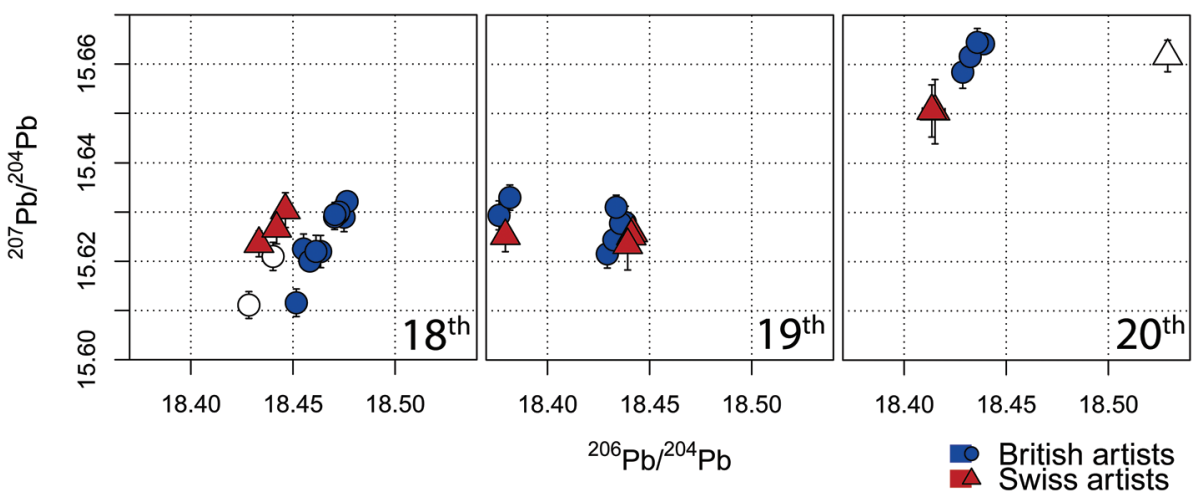

Fig. 3 Lead isotope ratios ( \pm standard deviation) for the sample collection of this project $\left({ }^{206} \mathrm{~Pb} /{ }^{204} \mathrm{~Pb}\right.$ vs. $\left.{ }^{207} \mathrm{~Pb} /{ }^{204} \mathrm{~Pb}\right)$. The paintings from British artist are labelled blue (points), the ones form Swiss Artists are red (triangles). The three different plots are separated based on the century of the signed date to the corresponding painting. The empty data points represent samples where the $\mathrm{CaCO}_{3}$-load can bias the lead isotope ratios. A representation of all the individually labelled results is given in the ESI (Fig. S7 $\dagger$ ). The number of data points is corresponding to the amount of different measurements (several replicates per paintings).

The whole isotope data set is in the range of 18.37-18.48 for the isotope abundance ratio ${ }^{206} \mathrm{~Pb} /{ }^{204} \mathrm{~Pb}$ and from $15.61-15.67$ for ${ }^{207} \mathrm{~Pb} /{ }^{204} \mathrm{~Pb}$. These values are in general agreement with prior literature concerning the age range $\left(17^{\text {th }}-20^{\text {th }}\right.$ century) and may constrain the geographical origin of the lead ore sources. ${ }^{6}$ All replicates show an expected grouping and a characteristic linearity in the ${ }^{206} \mathrm{~Pb} /{ }^{204} \mathrm{~Pb} v s .{ }^{207} \mathrm{~Pb} /{ }^{204} \mathrm{~Pb}$ plot, a feature often reported in $\mathrm{Pb}$-isotopes determination given by the uncertainty on the ${ }^{204} \mathrm{~Pb}$-signal.

A provenance distinction between samples collected from objects from Great Britain and Switzerland is not visually observed in Fig. 3, indeed one observes a rather clear overlap of the isotopic ratios.

In his pioneer work to archaeometric isotope ratio analysis, Keisch et al. (1976) introduced the "Lead Isotope Ratio Index" (LIRI), which combines the measured isotope ratios and plots it against the sample age (see Figure S8 $\dagger$ ). ${ }^{6}$ The results obtained in this study are in general agreement with their findings and can be integrated into the framework of lead isotope analysis concerning lead white pigments. We find a narrow distribution of the LIRI before 1850, which points to the signature of British ores (18.2-18.4). This observation correlates with the work of van Loon $(2019)^{49}$ and fits our expectation as the largest lead white producers of the time were the British and Dutch, which imported British lead, thus resulting in a narrow isotopic spread. Later in the $19^{\text {th }}$, more European ores (i.e. Germany/Austria) $)^{6,45}$ as well as influence from beyond Europe are to be expected but the calculated LIRI index for the set of studied samples stays fairly constant and does not indicate any apparent influence from globalization concerning the used lead source for lead white in our samples.

Nonetheless, when classifying the data per century, the direct comparison of the ratios ${ }^{206} \mathrm{~Pb} /{ }^{204} \mathrm{~Pb}$ vs. ${ }^{207} \mathrm{~Pb} /{ }^{204} \mathrm{~Pb}$, becomes clearer. In Fig. 3 the analyzed paintings are separated into $18^{\text {th }}, 19^{\text {th }}$ and $20^{\text {th }}$ century, which provides a better distinction of the lead isotopes' variations. Paintings originating in the $18^{\text {th }}$ century show a close grouping around 15.62 and
18.45 for ${ }^{207} \mathrm{~Pb} /{ }^{204} \mathrm{~Pb}$ and ${ }^{208} \mathrm{~Pb} /{ }^{204} \mathrm{~Pb}$ respectively. In the $19^{\text {th }}$ century, a transition phase is noticeable as the clustering gets larger: in particular, two sub-cluster can be identified, one overlapping with those from the $18^{\text {th }}$ century paintings while the second group has lower ${ }^{206} \mathrm{~Pb} /{ }^{204} \mathrm{~Pb}$ ratios of 18.38 . These latter ones relate to artworks dated after 1860 (LM-114651, Wells (duplicate)). The isotope ratios for the later work $\left(20^{\text {th }}\right.$ century), on the other hand show substantially higher ${ }^{207} \mathrm{~Pb} /{ }^{204} \mathrm{~Pb}$ which was also observed in the work by Stevenson (2016). ${ }^{9}$ When plotting the isotope ratios ${ }^{207} \mathrm{~Pb} /{ }^{206} \mathrm{~Pb} v$. ${ }^{208} \mathrm{~Pb} /{ }^{206} \mathrm{~Pb}$, (ESI: Figure $\mathrm{S} 9 \dagger$ ) a similar grouping for the individual periods is becoming apparent. The older paintings are characterized by lower values and both increase with the dated age. The transition phase for the $19^{\text {th }}$ century is again present. Most $19^{\text {th }}$ century belonging objects show a similar grouping with the data of the $18^{\text {th }}$ century. In particular, sample LM 161897 (1813) shows a very close overlaps and as already discussed, two exceptions dated after 1860 (LM-114651, Wells) show a distinct separation.

The isotope composition for lead ores all over Europe is given as a complicated, not always distinct distribution and some ore sources show some overlap. ${ }^{7,8}$ The presented data agree with reference data from several lead ore sites, in particular those from Great Britain (all), Germany (all), Poland $\left(17^{\text {th }} /\right.$ $\left.18^{\text {th }}\right)$, Spain $\left(20^{\text {th }}\right)$ and Netherlands $\left(19^{\text {th }} / 20^{\text {th }}\right)$. Solely there is no overlap with the data from Italian ores sites and it seems very unlikely that lead white from non-European lead ores are present in the listed sample set.\|

|| Lead white literature mentions significant difference in product quality and it is commonly agreed that the lead white denoted as Venetian white as well as Kremeserweiss are of superior class, rendering the purest white but are also the most expensive. ${ }^{52,54}$ Both products are locally produced and henceforth carry a defined $\mathrm{Pb}$ isotope fingerprint. Kremserweiss played an essential role on the continent since the late $18^{\text {th }}$ century and may explain the observed spreading in lead isotopic ratios. 


\section{Combined discussion}

The driving force of the study was to demonstrate the possibility of acquiring independently both age and provenance information from a single sample. Lead isotopes are typically conducted on less than $200 \mu \mathrm{g}$ material, thus the small sample sizes usually accessible, represent a limitation in regard to ${ }^{14} \mathrm{C}$ analysis. Technological advances in the last 20 years have revolutionized sample requirement and currently allow the routine measurement of samples of $10-50 \mu \mathrm{g} \mathrm{C}{ }^{29-31,50}$ thereby allowing to target pictorial layers.

Among the objects of study, the tacking margins of the British paintings (see Figure S3, ESI $\dagger$ ) which were removed upon lining the original canvases, were ideal in the sense that enough material was present (10-100 mg) and were collected in a passive manner, i.e. the lining process is a common practice, and the removal of tacking margins was an accepted part of the treatment at that time. After separation from the textile threads 3 to $30 \mathrm{mg}$ lead white bearing paint was collected, which resulted in 20-100 $\mu \mathrm{g} \mathrm{C}$ from the lead white pigment. Sample LM-161897 depicted in Fig. 1 was collected from the canvas corner edge below the frame, hereby providing $25 \mathrm{mg}$ material comprising textile and paint material. However not all artworks are framed and could be sampled below the frame nor are they painted over the edges, thus reducing the possibilities for discrete sampling. Figure S1/2 from the ESI $\uparrow$ illustrates the sampling of the Swiss artist's objects, where paint material was scratched off the edges of the work and amounted to 0.7 to $3 \mathrm{mg}$ material. Overall all collected samples provided sufficient material to conduct both ${ }^{14} \mathrm{C}$ analysis followed by lead isotope ratio analysis. Only sample LM-161803, which weighed $0.7 \mathrm{mg}$, represented not enough material for the analysis $(<10 \mu \mathrm{g}$ C from the carbonate, $<10 \mu \mathrm{g}$ remaining material for $\mathrm{Pb}$-analysis).

The results obtained in this study showcase the benefit of combining multiple (isotope-) techniques and use them as proxy to place an artwork in an historical context. The interpretation of the individual results coming from the two methods relies on additional information provided by historical context such as production process, raw material source involved and trading, etc. Overall, the data collected in the frame of this feasibility study delivers a consistent pattern between signed dates, their radiocarbon ages (see Fig. 2), their spread of the lead isotopes based on their age (see Fig. 3) and the comparisons with possible raw material sources.

However, this paper does not claim it can solve authentication cases alone. Indeed, the data set of this study was limited to about 20 paintings, a larger number of samples would be more representative. Furthermore, the aim of the presented work was not to present an in-depth art historical interpretation and discussion regarding the trade/production/ use of lead or lead white pigment but rather to demonstrate the successful approach in extracting supplementary information by combining isotopic analysis from a single lead white bearing paint sample.

\section{Conclusions}

Isotopes analysis are gaining much interest in studies of cultural heritage, but such information can only be accessed by destructive sampling, which is delicate considering this kind of samples. Due to the invasive action of radiocarbon dating, it is often only considered as a last resort, when no conclusive evidence could be reached with alternative techniques. In this study, we demonstrate that the sampling of lead white paint allows investigation of two isotope systems, namely carbon and lead, from one single sample hereby maximising the information output. The lead isotope ratio determination is relatively well established and was reported 40 years ago, whereas the ${ }^{14} \mathrm{C}$ dating of the lead white pigment is a new approach and technical improvements of the last 10 years enable work with much smaller sample sizes. The combination of the two methods is innovative, as the entire sample material is analysed namely both the anion and cation. The results of the proposed methodology offer a deeper understanding of the origin of the material under investigation, while keeping the sample requirements to a minimum as the two isotope systems are independent and can be analysed from the same sample.

The gathered data on the chosen examples from both Swiss and British artists covering the $18^{\text {th }}$ to $20^{\text {th }}$ centuries, show trends directly related to the lead white industry. Pb-isotopes give insight into the trading of the raw material i.e. up until 1860s a single cluster is observed, which points to a single source of lead (likely British ores), while after 1860 a larger spread in $\mathrm{Pb}$-isotope ratio is noticeable. The later points to increased mining activities in different ores sites across Europe, which correlates with industrial development. In order to successfully apply the methodology for authentication issues, a broader $\mathrm{Pb}$ isotope ratio database would help to support statements about geographical classifications, which has already been launched by other groups. Such broader campaigns are ongoing, namely a large project funded by the Netherlands Institute for Conservation, Art and Science (NICAS) entitled Multi-isotopic analysis of early modern art (MITEEMA). Unfortunately, at the time of this study, their results were not yet published. ${ }^{51}$

With respect to ${ }^{14} \mathrm{C}$ dating, the calibration of the ${ }^{14} \mathrm{C}$ ages will define the ambiguity of the data. In the frame of this validation study, the results were coherent with the signed date, hence demonstrating the proof of principle of the method. In real case applications, ${ }^{14} \mathrm{C}$ analysis is only considered in a last instance, as the method is both invasive and destructive. Moreover, when sampling is granted, the results are expected to be meaningful, i.e. provide a precise dating. When targeting a likely attribution between 1700-1950, however, no decisive evidence is possible using micro-sampling. In contrast, for objects belonging to other time periods, such as the $13^{\text {th }}$ century or created following the bomb peak (post-1950) a microscale approach is feasible. Hence, when considering uncertified objects, incoherencies between the different ${ }^{14} \mathrm{C}$ ages can be considered as red flags. For instance, if an attributed $16^{\text {th }}$ century painting displays a depleted ${ }^{14} \mathrm{C}$ lead white 
signal, synonym of $19^{\text {th }}$ century production, or an enriched signal typical for bomb peak material, it is an obvious chronological inconsistency. Unfortunately, today's rate of fossil fuel consumption and respective $\mathrm{CO}_{2}$ emission is reducing the relative content of the atmospheric ${ }^{14} \mathrm{C}$ content, which in turn no longer allows the conversion of ${ }^{14} \mathrm{C}$ ages to definite dates. In particular, if lead white is prepared within the next decade following the traditional method, its ${ }^{14} \mathrm{C}$ signal will show a similar ${ }^{14} \mathrm{C}$ signature to Roman or medieval periods, meaning that radiocarbon dating will be useless for objects with insufficient context.

The present discussion has been limited to the lead white pigment but did not extend to the paint matrix, which also carries information. The investigation of (ultra-)trace element composition of different pigments may be a further direction of research, to identify specific fingerprints related to origin, production or historic events, such as the nuclear weapon testing.

\section{Conflicts of interest}

There are no conflicts to declare.

\section{Acknowledgements}

The authors are thankful to Professor Aviva Burnstock from the Courtauld Institute of Art (London), who helped launching the project by providing samples. Unfortunately, the samples were too small and no data is shown. Additionally, the authors gratefully acknowledge the contribution of the HART project, in particular Dr Leslie Carlyle for providing lead white reference material which allowed preliminary feasibility studies. The authors wish to thank both the SIK-ISEA and SNM institutes for giving access to their painting collection. Also to be thanked is Erwin Hildbrand (SNM) for his help in discussing spectroscopic results and Natalie Ellwanger (SNM) for selecting the Swiss paintings and sampling. Financial and infrastructure support by ETH Zurich is greatly acknowledged, in particular grant ETH-21 15-1.

\section{Notes and references}

1 Theophrastus and D. E. Eichholz, De lapidibus, Clarendon Press, Oxford, 1965.

2 N. Eastaugh, Pigment compendium: a dictionary and optical microscopy of historical pigments, Butterworth-Heinemann, 2008.

3 R. Gettens and G. Stout, Painting materials: a short encyclopaedia, Courier Corporation, 1966.

4 R. J. Gettens, H. Kühn and W. T. Chase, Stud. Conserv., 1967, 12, 125-139.

5 A. G. Nord and K. Billström, Heritage Sci., 2018, 6, 25.

6 B. Keisch and R. C. Callahan, Archaeometry, 1976, 18, 181193.
7 G. Fortunato, A. Ritter and D. Fabian, Analyst, 2005, 130, 898.

8 D. Fabian and G. Fortunato, Tracing White: A Study of Lead White Pigments found in Seventeenth-Century Paintings using High Precision Lead Isotope Abundance Ratios, Archetype Publications, London, 2010.

9 R. K. Stevenson, E. A. Moffatt, M. C. Corbeil and A. Poirier, Archaeometry, 2016, 58, 673-687.

10 B. P. Johnson and J. Vermeer, Saint Praxedis, 1990, vol. 48.

11 M. Stols-Witlox, in Studying old master paintings: technology and practice: the National Gallery Technical Bulletin 30th anniversary conference postprints, Archetype Publications, London, 2011, pp. 284-294.

12 E. Homburg and J. H. De Vlieger, Hist. Technol., 1996, 13, 33-52.

13 D. J. Rowe, Lead manufacturing in Britain: A history, Routledge, London, 1st edn, 2017, vol. 16.

14 L. Beck, I. Caffy, E. Delqué-Količ, C. Moreau, J.-P. Dumoulin, M. Perron, H. Guichard and V. Jeammet, Commun. Chem., 2018, 1, 34.

15 L. Hendriks, I. Hajdas, E. S. B. Ferreira, N. C. Scherrer, S. Zumbühl, M. Küffner, L. Carlyle, H.-A. A. Synal and D. Günther, Radiocarbon, 2019, 61, 473-493.

16 L. Beck, C. Messager, S. Coelho, I. Caffy, E. Delqué-Količ, M. Perron, S. Mussard, J.-P. Dumoulin, C. Moreau, V. Gonzalez, E. Foy, F. Miserque and C. Bonnot-Diconne, Radiocarbon, 2019, 61, 1345-1356.

17 L. Hendriks, I. Hajdas, E. S. B. Ferreira, N. C. Scherrer, S. Zumbühl, M. Küffner, L. Wacker, H.-A. A. Synal and D. Günther, Radiocarbon, 2018, 60, 207-218.

18 L. Carlyle, De Mayerne Programme HART Report 2002-2005, 2005.

19 Q. G. Zeng, G. X. Zhang, C. W. Leung and J. Zuo, Microchem. J., 2010, 96, 330-336.

20 M. L. Amadori, G. Poldi, S. Barcelli, P. Baraldi, M. Berzioli, A. Casoli, S. Marras, G. Pojana and G. C. F. Villa, Spectrochim. Acta, Part A, 2016, 164, 110-122.

21 F. Bruhn, A. Duhr, P. M. Grootes, A. Mintrop and M.-J. Nadeau, Radiocarbon, 2001, 43, 229-237.

22 I. Hajdas, E\&G Quat. Sci. J., 2008, 57, 2-24.

23 L. Wacker, M. Němec and J. Bourquin, Nucl. Instrum. Methods Phys. Res., Sect. B, 2010, 268, 931-934.

24 L. Hendriks, et al., in preparation.

25 H. A. Synal, M. Stocker and M. Suter, Nucl. Instrum. Methods Phys. Res., Sect. B, 2007, 259, 7-13.

26 L. Wacker, G. Bonani, M. Friedrich, I. Hajdas, B. Kromer, M. Němec, M. Ruff, M. Suter, H. A. Synal and C. Vockenhuber, Radiocarbon, 2010, 52, 252-262.

27 S. M. Fahrni, L. Wacker, H. A. Synal and S. Szidat, in Nuclear Instruments and Methods in Physics Research, Section B: Beam Interactions with Materials and Atoms, NorthHolland, 2013, vol. 294, pp. 320-327.

28 L. Wacker, S. M. Fahrni, I. Hajdas, M. Molnar, H. A. Synal, S. Szidat and Y. L. Zhang, in Nuclear Instruments and Methods in Physics Research, Section B: Beam Interactions with Materials and Atoms, North-Holland, 2013, vol. 294, pp. 315-319. 
29 M. Ruff, S. Szidat, H. W. Gäggeler, M. Suter, H.-A. Synal and L. Wacker, Nucl. Instrum. Methods Phys. Res., Sect. B, 2010, 268, 790-794.

30 S. M. Fahrni, H. W. Gäggeler, I. Hajdas, M. Ruff, S. Szidat and L. Wacker, Nucl. Instrum. Methods Phys. Res., Sect. B, 2010, 268, 787-789.

31 M. Ruff, S. Fahrni, H. W. Gäggeler, I. Hajdas, M. Suter, H. A. Synal, S. Szidat and L. Wacker, Radiocarbon, 2010, 52, 1645-1656.

32 C. B. Ramsey, Quat. Sci. Rev., 2008, 27, 42-60.

33 C. B. Ramsey, Radiocarbon, 2009, 51, 337-360.

34 H. P. Longerich, B. J. Fryer and D. F. Strong, Spectrochim. Acta, Part B, 1987, 42, 39-48.

35 F. Albarède, P. Telouk, J. Blichert-Toft, M. Boyet, A. Agranier and B. Nelson, Geochim. Cosmochim. Acta, 2004, 68, 2725-2744.

36 W. Todt, R. A. Cliff, A. Hanser and A. W. Hoffmannm, in Earth Processes: Reading the Isotopic Code, ed. A. R. Basu and S. R. Hart, American Geophysical Union, Washington, D. C., 95th edn, 1996, pp. 429-437.

37 E. J. Catanzaro, T. J. Murphy, W. R. Shields and E. L. Garner, J. Res. Natl. Bur. Stand. Sect. A Phys. Chem., 1968, 72, 261.

38 P. J. Reimer, E. Bard, A. Bayliss, J. W. Beck, P. G. Blackwell, C. B. Ramsey, C. E. Buck, H. Cheng, R. L. Edwards, M. Friedrich, P. M. Grootes, T. P. Guilderson, H. Haflidason, I. Hajdas, C. Hatté, T. J. Heaton, D. L. Hoffmann, A. G. Hogg, K. A. Hughen, K. F. Kaiser, B. Kromer, S. W. Manning, M. Niu, R. W. Reimer, D. A. Richards, E. M. Scott, J. R. Southon, R. A. Staff, C. S. M. Turney and J. van der Plicht, Radiocarbon, 2013, 55, 1869-1887.

39 Q. Hua, M. Barbetti and A. Z. Rakowski, Radiocarbon, 2013, 55, 2059-2072.

40 A. J. T. Jull, Nucl. News, 1998, 41, 30-38.
41 H. E. Suess, Science, 1955, 122, 415-417.

42 H. E. Suess, J. Geophys. Res., 1965, 70, 5937-5952.

43 C. D. Keeling, W. G. Mook and P. P. Tans, Nature, 1979, 277, 121-123.

44 M. Stols-Witlox, L. Megens and L. Carlyle, 'To prepare white excellent...': reconstructions investigating the influence of washing, grinding and decanting of stack-process lead white on pigment composition and particle size, Archetype Publications, 2012.

45 W. Pulsifer, Notes for a history of lead: and an inquiry into the development of the manufacture of white lead and lead oxides, D. Van Nostrand, 1888.

46 F. Brock, N. Eastaugh, T. Ford and J. H. Townsend, Radiocarbon, 2019, 61, 39-49.

47 R. J. Gettens, E. W. FitzHugh and R. L. Feller, Stud. Conserv., 1974, 19, 157-184.

48 S. Baron, C. Le-Carlier, J. Carignan and A. Ploquin, Appl. Geochem., 2009, 24, 2093-2101.

49 A. van Loon, A. Vandivere, J. K. Delaney, K. A. Dooley, S. De Meyer, F. Vanmeert, V. Gonzalez, K. Janssens, E. Leonhardt, R. Haswell, S. de Groot, P. D’Imporzano and G. R. Davies, Heritage Sci., 2019, 7, 1-20.

50 C. Welte, L. Hendriks, L. Wacker, N. Haghipour, T. I. Eglinton, D. Günther and H. A. Synal, Nucl. Instrum. Methods Phys. Res., Sect. B, 2018, 437, 66-74.

51 P. D’Imporzano, K. Keune, J. M. Koornneef, E. Hermens, P. Noble and G. R. Davies, in Technart2019, 2019.

52 C. F. Prange, Farbenlexicon, Hendel, 1782.

53 J. A. Weber, Bekannte und unbekannte Fabriken und Künste, aus eigener Erfahrung, Heerbrandt, 1781.

54 C. F. A. Hochheimer, Chemische Farben-Lehre oder ausführlicher Unterricht von Bereitung der Farben zu allen Arten der Malerey, Gräff, 1803. 